\title{
IDENTIFIKASI BAHAYA LONGSOR LAHAN DI SEBAGIAN WILAYAH PONCOKUSUMO DAN WAJAK KABUPATEN MALANG
}

\author{
Listyo Yudha Irawan*, Ade Yulyanto, Ahmad Zaini T.S, Anang Ma'ruf, \\ Elok Nailatus Sa'idah, Fadel Mahardhika Setiawan \\ Jurusan Geografi, Fakultas Ilmu Sosial, Universitas Negeri Malang, Malang, Indonesia \\ *Email Koresponden: listyo.fis@um.ac.id \\ Diterima: 14-08-2020, Revisi: 17-12-2020, Disetujui: 19-12-2020 \\ (C)2020 Program Studi Pendidikan Geografi, FISE, Universitas Hamzanwadi
}

\begin{abstract}
Abstrak Wilayah Poncokusumo dan Wajak merupakan salah satu kecamatan di Kabupaten Malang. Poncokusumo dan Wajak memiliki penggunaan lahan, geologi, dan morfogenesis yang bervariasi. Kondisi fisiografis tersebut berpengaruh terhadap peningkatan ancaman bahaya longsor. Penelitian ini bertujuan untuk mengetahui tingkat bahaya longsor lahan dan persebarannya. Metode yang digunakan dalam identifikasi bahaya longsor yaitu metode skoring yang mengacu pada Peraturan Kepala BNPB Tahun 2012, Standar Nasional Indonesia (SNI) nomor 13-7124-2005, Metode Tidak Langsung, dan Risiko Bencana Indonesia (RBI) BNPB Tahun 2016. Hasil penelitian menunjukkan bahwa kondisi geologi wilayah penelitian tersusun atas material gunungapi seperti lahar dan endapan lahar. Material tersebut bersifat lepas dan tidak stabil. Berdasarkan klasifikasi kemiringan lereng wilayah ini terdiri dari daerah yang datar dengan kemiringan $0-8 \%$ hingga daerah yang curam dengan kemiringan $>40 \%$. Berdasarkan kondisi morfologinya dapat diketahui bahwa wilayah ini merupakan wilayah rawan terhadap kejadian longsor. Tingkat bahaya longsor lahan di sebagian wilayah Poncokusumo dan Wajak adalah rendah dan sedang. Tingkat bahaya longsor lahan rendah didominasi oleh penggunaan lahan hutan. Tingkat bahaya bencana lonsor sedang didominasi oleh penggunaan lahan permukiman. Luas wilayah dengan tingkat bahaya rendah adalah $860,8 \mathrm{Ha}$ dan luas tingkat bahaya sedang adalah $365,1 \mathrm{Ha}$.
\end{abstract}

Kata kunci: longsor, bahaya, SIG

\begin{abstract}
Poncokusumo and Wajak regions are one of the Districts in Malang Regency. Poncokusumo and Wajak have varied land uses, geology and morphogenesis. This physiographic condition has an effect on the increasing threat of landslides. This study aims to determine the level of landslide hazard and its distribution. The method used in the identification of landslide hazards is the scoring method which refers to the 2012 BNPB Head Regulation, Indonesian National Standard number 13-7124-2005, the Indirect Method, and the Indonesian Disaster Risk (RBI) BNPB 2016. The results showed that the geological conditions of the study area were composed of volcanic materials such as lava and lava deposits. This material is loose and unstable. Based on the slope classification, this area consists of flat areas with a slope of $0-8 \%$ to steep areas with a slope of $>40 \%$. Based on the morphological conditions, it can be seen that this area is an area prone to landslides. Landslide hazard levels in parts of Poncokusumo and Wajak are low and medium. Low landslide hazard levels are dominated by forest land use. The level of danger of a lonsor is being dominated by the use of residential land. The area with a low hazard level is $860.8 \mathrm{Ha}$ and the area with a moderate hazard level is $365.1 \mathrm{Ha}$.
\end{abstract}

Keywords: landslide, hazard, GIS

\section{PENDAHULUAN}

Kecamatan Poncokusumo dan Wajak merupakan bagian dari Kabupaten Malang. Sebagian wilayah ini memiliki kondisi morfologi yang bervariasi. Kondisi morfologi tersebut mulai dari datar hingga miring. Kemiringan lereng merupakan salah satu parameter dalam proses geomorfologi di permukaan bumi (Bachri et. al., 2019). Daerah dengan morfologi miring pada umumnya memiliki ancaman kejadian longsor lebih besar daripada daerah dengan morfologi datar. Lereng yang tersusun oleh perlapisan batuan yang miring searah kemiringan lereng sering terjadi luncuran batuan atau luncuran bahan rombakan dengan kecepatan tinggi (Priyono \& Priyana, 2006). Luncuran tersebut 
terjadi di sepanjang bidang-bidang perlapisan batuan yang merupakan bidang yang lemah, terutama apabila terjadi tekanan oleh air yang meresap melalui bidang-bidang tersebut. Meresapnya air hujan melalui bidang-bidang retakan batuan pada lereng di daerah tersebut merupakan pemicu terjadinya gerakan. Air yang mengisi retakan-retakan batuan bersifat menekan dan semakin melemahkan kekuatan batuan untuk tetap stabil, akhirnya blok-blok batuan bergerak meluncur ke bawah lereng.

Secara morfogenesis, sebagian wilayah Poncokusumo dan Wajak berasal dari proses vulkanik Gunungapi Bromo, Tengger, dan Semeru. Daerah ini tersusun oleh material hasil endapan vulkan seperti: lahar, kerikil, pasir dan endapan. Meterial-material tersebut sebagian besar bersifat lepas sehingga, mengakibatkan rawan terjadi longsor. Pada umumnya di daerah pegunungan yang ditutupi oleh lapisan tanah penutup yang lunak/gembur, air hujan dapat dengan mudah merembes pada tanah yang gembur dan batuan lempung yang berongga atau retak-retak (Priyono \& Priyana, 2006). Air rembesan ini berkumpul antara tanah penutup dan batuan asal yang segar pada lapisan alas yang kedap air. Tempat air rembesan ini berkumpul dapat berfungsi sebagai bidang luncur. Meningkatnya kadar air dalam lapisan tanah atau batuan, terutama pada lereng-lereng bukit akan mempermudah gerakan bergeser atau tanah longsor. Penggunaan lahan merupakan salah satu faktor yang berpengaruh terhadap kondisi lingkungan. Penggunaan lahan yang tidak sesuai peruntukan dapat menimbulkan dampak negatif bagi lingkungan seperti: peningkatan laju erosi, limpasan permukaan, tanah longsor hingga banjir.

Kondisi di wilayah penelitian menunjukan bahwa terdapat masyarakat di sebagian wilayah Poncokusumo dan Wajak mendirikan bangunan di lokasi lereng dengan kondisi miring. Bagian lereng dengan topografi miring seharusnya digunakan sebagai kawasan konservasi. Upaya konservasi dimaksudkan untuk melakukan perlindungan, perbaikan, dan pemakaian sumber daya alam sesuai dengan prinsip-prinsip yang dapat menjamin keuntungan ekonomi atau sosial yang tertinggi secara lestari (Salim \& Agustina 2018). Kawasan konservasi dengan berbagai macam tumbuhan berfungsi untuk mengikat tanah agar tidak mudah longsor. Selain itu, daerah tersebut memiliki curah hujan yang tergolong tinggi. Sebagai akibat dari kondisi tersebut tanah yang ada di lereng miring akan terkikis secara perlahan-lahan dan terjadi longsor.

Beberapa penelitian menunjukkan pentingnya melakukan analisis atau identifikasi bahaya dan risiko longsor lahan sebagai upaya pengurangan risiko bencana. Buchori \& Susilo (2012) mengujicoba model keruangan dengan pendekatan SIG untuk mengidentifikasi kawasan rawan longsor, ia menemukan model tersebut bekerja dengan baik dengan validitas 92,5\%. Beberapa penelitian lainnya menganalisis tingkat dan sebaran bahaya longsor dengan metode yang berbeda. Permadi et al., (2018) menggunakan Multi Criteria Evaluation; Ramadhani \& Idajati (2017) menggunakan metode pembobotan AHP untuk analisis overlay weighted sum; Nursa'ban (2010) menggunakan overlay dan uji laboraturium; Wahyuningrum \& Supangat (2016) mengidentifikasi bahaya longsor dengan metode kombinasi peta dengan skala berbeda. Ini ditujukan untuk ketelitian hasil kajian. Priyono (2012) menggunakan integrasi analisis model medan digital dan Pedogeomorfik untuk kejadian bencana longsor. Kajian ini hanya bersifat literature review, sehingga perlu pengujian lebih lanjut untuk mengetahui metode tersebut. Dari beberapa penelitian dan kajian tersebut sebagian besar memetakan tingkat bahaya longsor di suatu wilayah. Dengan mengandalkan pendekatan Sistem Informasi Geografis, analisis dilakukan dengan beragam jenis indikator. Namun pada penelitian ini dengan pendekatan SIG, identifikasi bahaya longsor lahan dianalisis dengan metode dan indikator yang dikombinasikan dari SNI nomot 13-7124-2005 dan Buku Risiko Bencana Indonesia (RBI) BNPB Tahun 2016. Sehingga diharapkan hasil penelitian ini dapat memberikan tambahan khazanah pengetahuan khususnya terkait identifikasi bahaya longsor lahan di sebagian wilayah Kabupaten Malang.

Berdasarkan kondisi fisik seperti geologi dan geomorfologi, sebagian wilayah Poncokusumo dan Wajak merupakan daerah yang berpotensi terhadap ancaman bencana longsor lahan. Longsor lahan merupakan salah satu bencana yang sering terjadi dan menimbulkan kerugian, kerusakan, dan kehilangan. Salah satu upaya pencegahan untuk meminimalisasi dampak yang ditimbulkan adalah dengan cara melakukan pemetaan daerah-daerah rawan longsor. Penelitian ini bertujuan untuk mengetahui persebaran dan tingkat bahaya longsor lahan di sebagian wilayah Poncokusumo dan Wajak. Deteksi awal kejadian longsor dilakukan melalui deteksi berdasarkan Peta RBI Lembar Tumpang. 


\section{METODE PENELITIAN}

Lokasi penelitian dilakukan di beberapa desa yang terletak di Kecamatan Poncokusumo dan Wajak Kabupaten Malang. Beberapa desa tersebut adalah Desa Wajak, Desa Sumberejo, Desa Dawuhan, Desa Belayu dan Desa Patokpicis. Kecamatan Poncokusumo dan Wajak dipilih menjadi lokasi penelitian karena merupakan bagian dari formasi Gunungapi Bromo-Tengger-Semeru yang terletak di bagian barat. Wilayah kajian memiliki lokasi-lokasi yang rawan terhadap kejadian longsor.

Data yang digunakan dalam penelitian ini meliputi data primer dan data sekunder. Data primer yang meliputi hasil groundcheck lapangan untuk memvalidasi pemetaan tingkat bahaya longsor. Pemetaan tingkat bahaya longsor diperoleh dari peta tentatif. Peta tentatif yang digunakan dalam pemetaan tingkat bahaya longsor lahan adalah hasil overlay dari peta kemiringan lereng, peta penggunaan lahan dan peta geologi (Zhao \& Lu, 2018). Data sekunder yang digunakan antara lain DEM ALOS Palsar resolusi 12,5 $\mathrm{m}$, citra Sentinel 2A resolusi $10 \mathrm{~m}$, Peta Geologi Lembar Ampelgading dan Peta RBI Lembar Tumpang 1607-443. Citra sentinel dapat digunakan untuk identifikasi daerah rawan bencana berupa analisis kondisi geomorfologi, analisis vegetasi, serta analisis wilayah yang luas (Pradhan \& Kim, 2016; Pradana et al., 2020).

Teknik analisis data yang digunakan adalah teknik skoring dengan mengacu pada metode dan indikator SNI nomor 13-7124-2005 dan Buku Risiko Bencana Indonesia (RBI) BNPB Tahun 2016. Pada Peta Zona Kerentanan Gerakan Tanah dan Peta Kemiringan Lereng $>15 \%$, dilakukan skoring. Hasil peta tersebut kemudian di-overlay untuk mendapatkan peta bahaya longsor. Penentuan nilai skor pada zona kerentanan gerakan tanah dan perhitungan indeks bahaya dapat dilihat pada Tabel 1. Penentuan nilai skor pada kemiringan lereng $>15 \%$ dapat dilihat pada Tabel 2. Penentuan tingkat bahaya longsor dapat dilihat pada Tabel 3 .

Tabel 1. Penentuan Kelas Zona Kerentanan Gerakan Tanah dan Perhitungan Indeks Bahaya

\begin{tabular}{cc}
\hline Zona Kerentanan Gerakan Tanah & Nilai Kelas \\
\hline Sangat Rendah & 1 \\
Rendah & 2 \\
Sedang & 3 \\
Tinggi & 4 \\
Sangat Tinggi & 5 \\
\hline
\end{tabular}

Sumber: SNI nomor 13-7124-2005.

Tabel 2.Penentuan Kemiringan Lereng

\begin{tabular}{cc}
\hline Kelas Kemiringaan Lereng & Nilai Kelas \\
\hline $15-30 \%$ & 1 \\
$30-50 \%$ & 2 \\
$50-70 \%$ & 3 \\
$>70 \%$ & 4 \\
\hline
\end{tabular}

Sumber: Buku Risiko Bencana Indonesia, 2016.

Tabel 3. Penentuan Bahaya Longsor

\begin{tabular}{|c|c|c|}
\hline $\begin{array}{l}\text { Perhitungan } \\
\text { indeks bahaya }\end{array}$ & Indeks Bahaya & $\begin{array}{l}\text { Tingkat } \\
\text { Bahaya }\end{array}$ \\
\hline $\begin{array}{l}\text { Nilai kelas/ nilai } \\
\text { kelas maksimal }\end{array}$ & $\begin{array}{c}0,-0,333333 \\
0,333334-0,666666 \\
0,666667-1\end{array}$ & $\begin{array}{l}\text { Rendah } \\
\text { Sedang } \\
\text { Tinggi }\end{array}$ \\
\hline
\end{tabular}

Sumber: Peraturan Kepala BNPB, 2012. 
Diagram alir penlitian dapat dilihat pada Gambar 1 sebagai berikut.

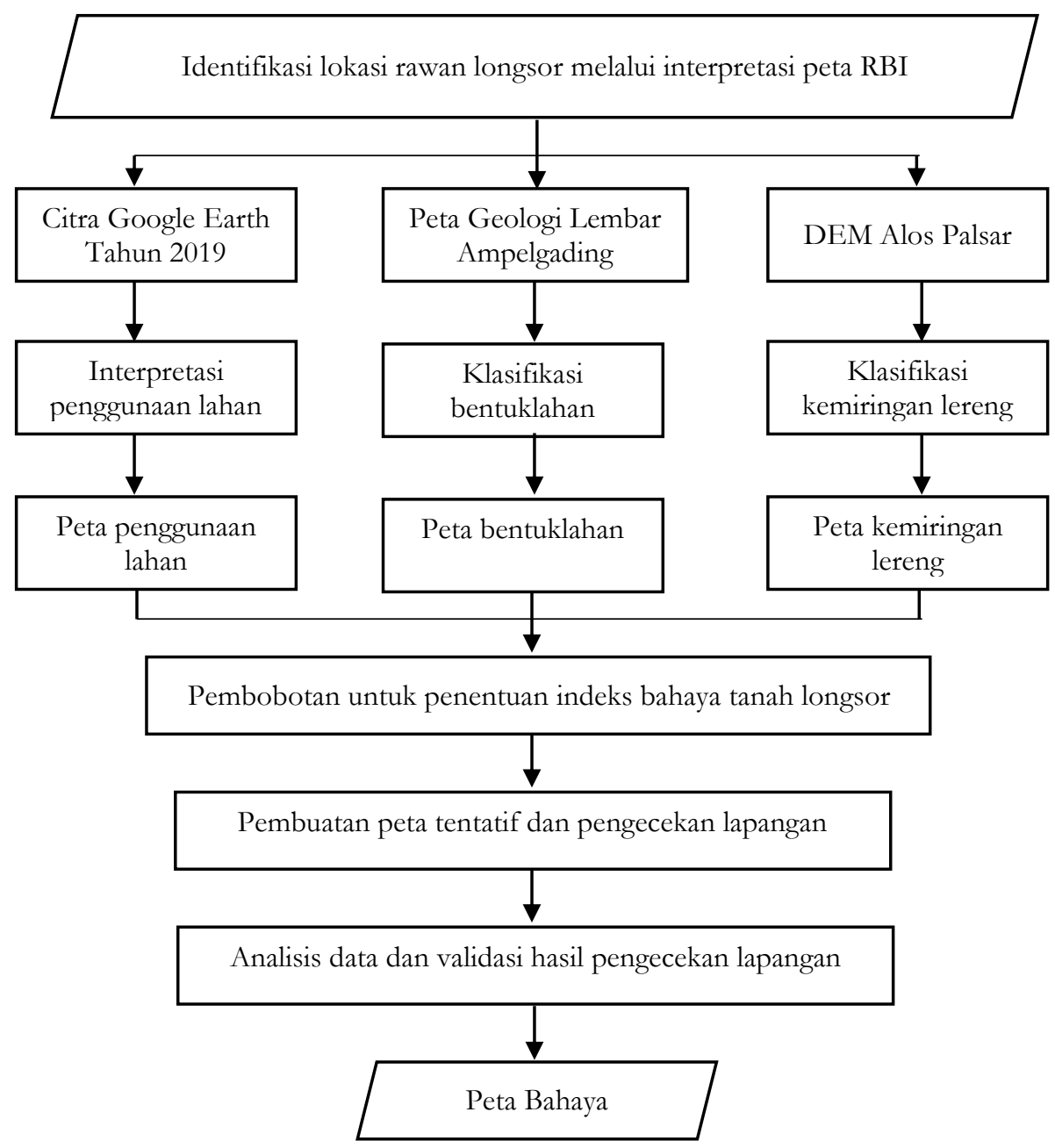

Gambar 1. Diagram alir tahapan penelitian identifikasi bahaya longsor Kecamatan Poncokusumo dan Wajak (Sumber: Peneliti, 2020)

\section{TEMUAN DAN PEMBAHASAN}

Deteksi dan analisis wilayah rawan longsor dapat dilakukan menggunakan pendekatan penginderaan jauh dan sistem informasi geografis (Feizizadeh \& Blaschke, 2011; Moayedi et al., 2019). Lokasi penelitian di sebagian wilayah Poncokusumo dan Wajak memiliki penggunaan lahan yang bervariasi. Penggunaan lahan yang ada di sebagian wilayah Poncokusumo dan Wajak antara lain dimanfaatkan untuk permukiman, hutan, tegalan, dan sawah. Berdasarkan peta penggunaan lahan tahun 2018 dapat diketahui luasan penggunaan lahan diantaranya: $3490 \mathrm{Ha}$ atau 75,25\% lahan digunakan untuk tegalan, $4980 \mathrm{Ha}(10,74 \%)$ untuk permukiman, $1870 \mathrm{Ha}(4,03 \%)$ digunakan untuk hutan, dan $4630 \mathrm{Ha}(9,98 \%)$ digunakan untuk sawah. Variasi penggunaan lahan yang ada di sebagian wilayah Poncokusumo dan Wajak dipengaruhi terutama oleh kondisi geografis dan sosial. Peta penggunaan lahan di lokasi penelitian dapat dilihat pada Gambar 2.

Kondisi geologi sebagian wilayah Poncokusumo dan Wajak merupakan wilayah yang tersusun atas material vulkan. Wilayah ini terdiri dari empat formasi geologi meliputi: Qvf, Qvom2, Qvtl dan Qvt. Formasi Qvf merupakan formasi yang tersusun atas material lahar Gunung Mahameru. Formasi Qvom2 tersusun atas material Gunungapi Tua Gunung Mahameru. Formasi Qvtl tersusun atas material lahar Gunung Tengger. Formasi Qvt terdiri dari endapan Gunungapi Tengger. Berdasarkan kondisi geologi tersebut dapat diketahui bahwa wilayah ini tersusun atas material gunungapi seperti lahar dan endapan lahar. Material tersebut merupakan material yang bersifat lepas dan tidak stabil. Selain itu, 
wilayah tersebut juga memiliki lapisan tanah yang lunak/gembur dengan solum tanah yang tebal. Kondisi tersebut berdampak pada kerawanan untuk terjadi gerakan tanah terutama ketika terjadi hujan dengan intensitas yang tinggi. Peta geologi wilayah kajian dapat dilihat dalam Gambar 3.

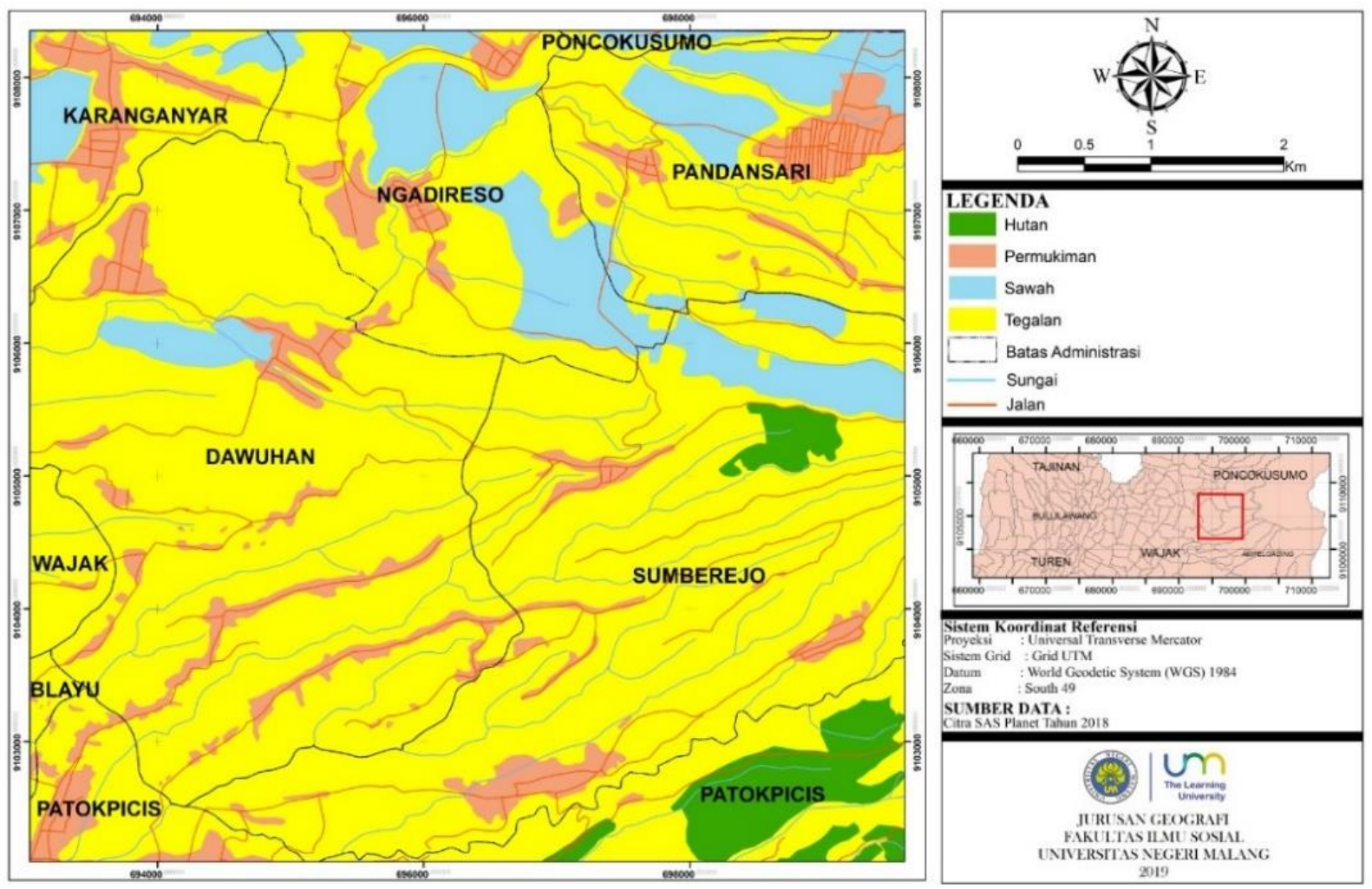

Gambar 2. Peta Penggunaan Lahan di sebagian wilayah Poncokusumo dan Wajak (Sumber: Peta RBI Digital, Badan Informasi Geospasial, 2018)
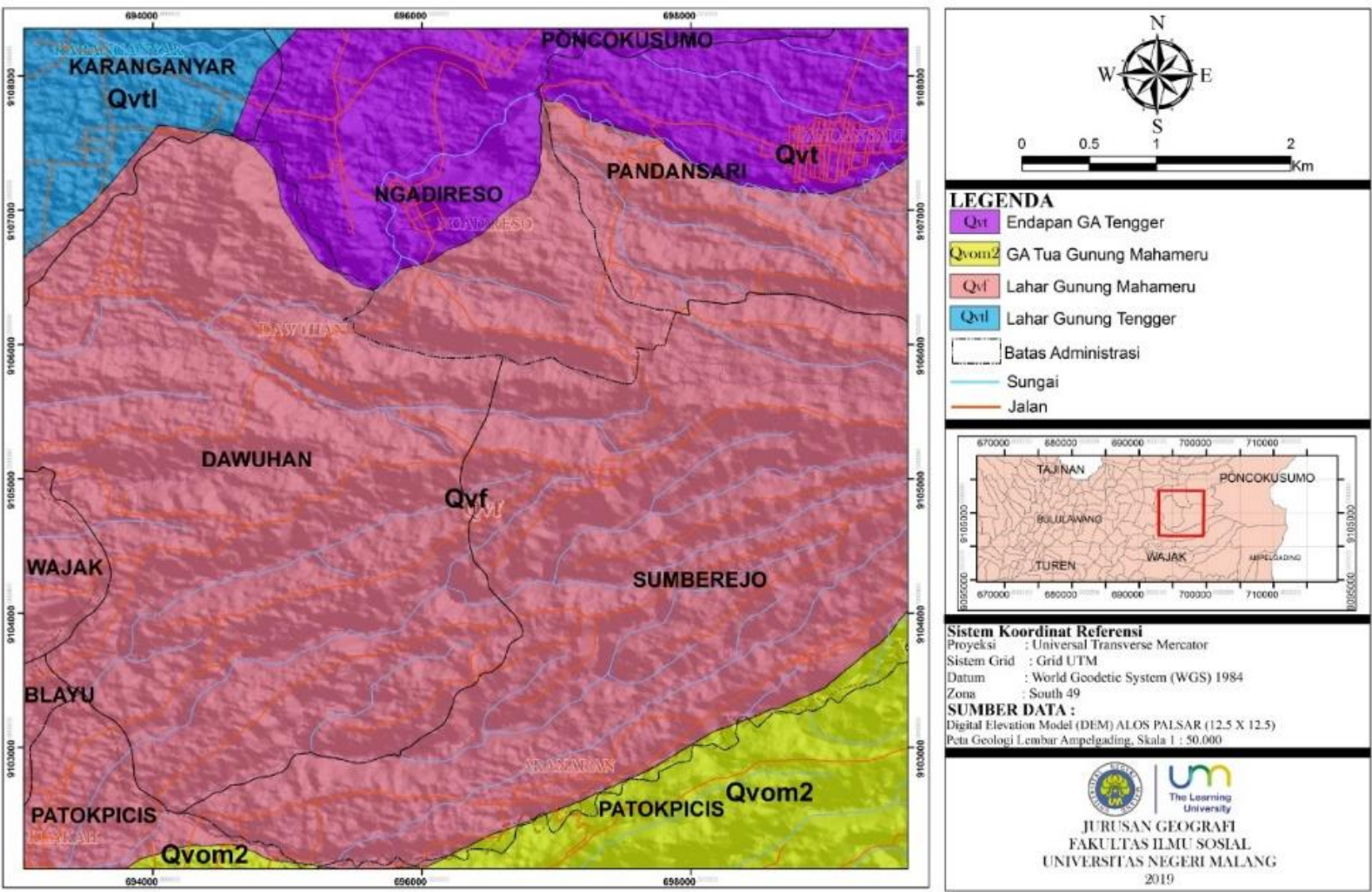

Gambar 3. Peta Geologi di sebagian wilayah Poncokusumo dan Wajak (Sumber: Peta Geologi Lembar Ampelgading) 


\section{Kondisi Morfologi di Lokasi Penelitian}

Secara umum sebagian wilayah Poncokusumo dan Wajak memiliki kondisi morfologi yang bervariasi. Kondisi morfologi tersebut mulai dari dataran hingga perbukitan yang terjal. Berdasarkan klasifikasi kemiringan lereng wilayah ini terdiri dari daerah yang datar dengan kemiringan $0-8 \%$ hingga daerah yang curam dengan kemiringan $>40 \%$. Di wilayah kajian juga terdapat lembah-lembah curam hasil aliran lahar dan air yang berbentuk $\mathrm{V}$ khas daerah vulkan. Bervariasinya kondisi morfologi yang ada di wilayah ini tidak lepas dari wilayahnya yang berada pada dataran fluvial gunungapi hingga lereng tengah gunungapi. Kondisi morfologi merupakan salah satu faktor yang sangat mempengaruhi kejadian longsor (Wang et al., 2016). Berdasarkan kondisi morfologinya dapat diketahui bahwa wilayah ini merupakan wilayah rawan terhadap kejadian longsor. Hal ini dikarenakan kondisi morfologi wilayahnya yang miring hingga curam/terjal. Karakteristik morfologi lahan terjal memiliki potensi kejadian longsor yang tinggi. Berikut merupakan kenampakan kondisi morfologi di sebagian wilayah Poncokusumo dan Wajak dapat dilihat dalam Gambar 4.

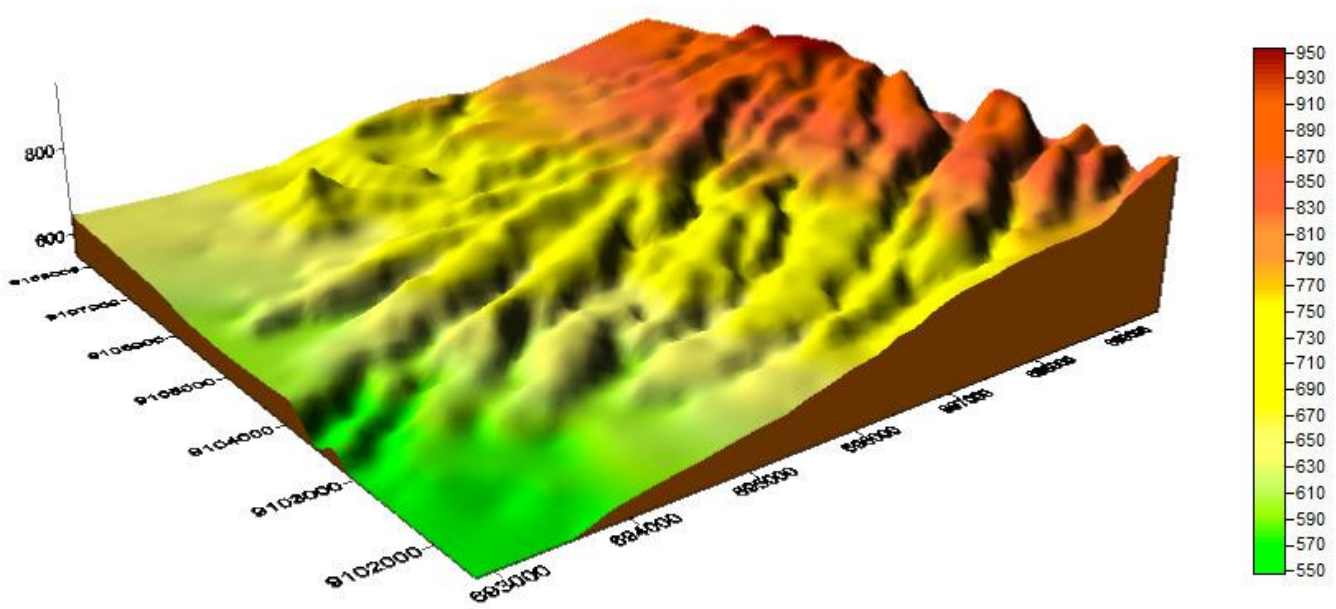

Gambar 4. Kenampakan morfologi di sebagian wilayah Poncokusumo dan Wajak (Sumber: Modelling 3D Morfologi Wilayah Penelitian, 2020)

\section{Klasifikasi Bentuklahan di Lokasi Penelitian}

Hasil identifikasi yang telah dilakukan menunjukan bahwa wilayah penelitian memiliki bentuklahan yang beragam. Bentuklahan yang teridentifikasi antara lain: D4V8, D4F1, D5V8, B1V8, T3V4. Penamaan simbol tersebut didasarkan pada kondisi morfologi, khususnya material permukaan serta morfoaransemen di lokasi penelitian. Pada bentuklahan D4V8, menunjukkan bahwa wilayah ini berupa daerah dengan morfologi datar, dengan material permukaannya berupa endapan hasil Gunungapi Tengger yang berada di dataran fluvial. Pada bentuklahan D4F1, menunjukkan bahwa wilayah ini berupa daerah dengan morfologi datar, dengan material permukaannya berupa endapan hasil Gunungapi Tengger yang berada di dataran aluvial. Pada bentuklahan D5V8, menunjukkan bahwa wilayah ini berupa daerah dengan morfologi datar, dengan material permukaannya berupa lahar Gunungapi Tengger yang berada di dataran fluvial. Pada bentuklahan B1V8, menunjukkan bahwa wilayah ini berupa daerah dengan morfologi bergelombang, dengan material permukaannya berupa lahar Gunungapi Mahameru yang berada di dataran fluvial. Pada bentuklahan T3V4, menunjukkan bahwa wilayah ini berupa daerah dengan morfologi terjal, dengan material permukaannya berupa endapan Gunungapi Mahameru dan Gunungapi Tengger yang berada di lereng gunungapi tengah.

Berdasarkan kondisi geomorfologi umumnya, bahwa sebagian besar daerah penelitian ini dipengaruhi oleh proses/aktivitas vulkan yang dominan. Secara geomorfologis wilayah penelitian termasuk bentukan asal vulkan. Bentuklahan asal proses vulkanik lebih didasarkan pada material atau jenis batuan penyusun berupa batuan vulkanik dengan berbagai jenisnya (Dibyosaputro, 1997). Pada bentuk asal proses vulkan, proses-proses geomorfologi vulkanik, baik yang bersifat endogen akibat gerakan magma ke permukaan bumi, maupun eksogen akibat aliran lava dan lahar, sangat menentukan 
perkembangan morfologi lereng dan bentanglahan Gunungapi Semeru dan Gunungapi Tengger yang sangat mempengaruhi kondisi morfologi wilayah kajian.

Pada wilayah kajian terdapat tiga macam bentuklahan berdasarkan morfoaransemennya yaitu: lereng tengah gunungapi, dataran fluvial gunungapi, dan dataran aluvial. Pada dataran fluvial gunungapi merupakan satuan bentuklahan yang lebih datar dan terbentuk dari pengendapan material oleh proses fluvial. Proses sedimentasi yang lebih dominan dibanding erosi di lembah sungai mulai aktif karena adanya penurunan kemiringan lereng yang memungkinkan terjadinya pengendapan yang cukup besar. Kemiringan lerengnya bervariasi dari agak landai sampai landai. Pemanfaatan lahan untuk pertanian mulai berkembang. Hal ini dapat dilihat dari penggunaan lahannya. Material permukaan didominasi oleh kerikil hingga pasir kasar. Proses erosi pada unit ini mulai lebih kecil dari pengendapannya. Secara umum proses erosi yang tampak adalah dari erosi alur dan sebagian terdapat longsoran kecil dibeberapa tempat. Kondisi tersebut dapat dilihat dari hasil pengecekan lapangan.

Pada lereng tengah gunungapi proses yang lebih dominan berupa pengangkutan material secara gravitatif dan oleh tenaga air. Lereng terbentuk dari hasil endapan material erupsi yang berlangsung secara bertahap. Kemiringan lereng di satuan bentuklahan ini bervariasi dari curam sampai agak curam dengan kondisi morofologi yang bergelombang hingga terjal. Adanya aktivitas longsor lahan dan pengangkutan oleh air dibeberapa titik yang lebih besar dibandingkan pada daerah dataran fluvial gunung api. Ciri lain yang umum adalah telah digunakannya untuk lahan pertanian, permukiman, peternakan, perkebunan dan pariwisata. Biasanya lereng gunungapi ini memiliki bentuk yang belum teratur dengan lembah-lembah yang dalam (Santosa, 2006). Peta bentuklahan lokasi penelitian dapat dilihat dalam Gambar 5 sebagai berikut.

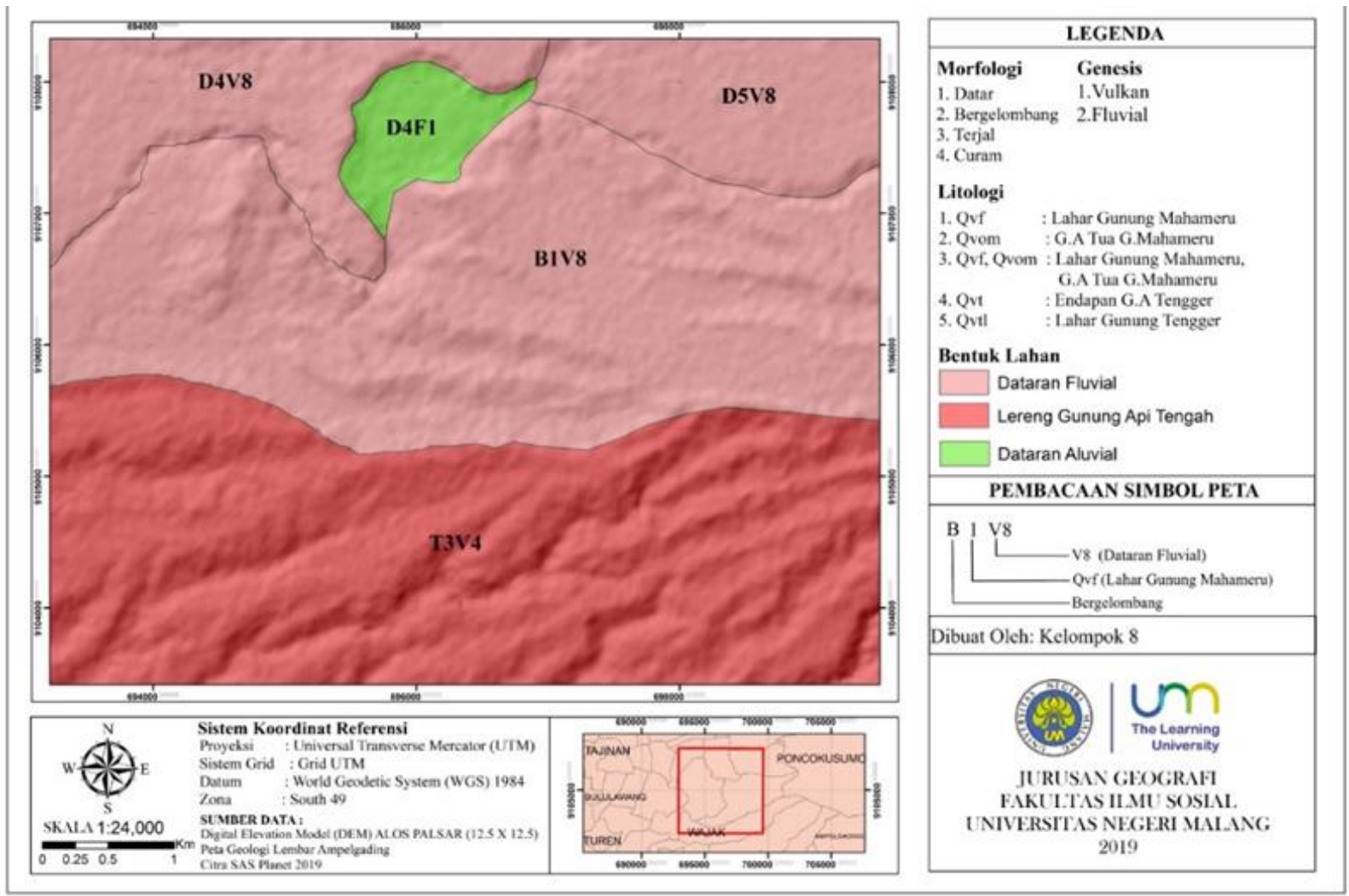

Gambar 5. Peta Geomorfologi di sebagian wilayah Poncokusumo dan Wajak (Sumber: Peta Geologi Lembar Ampelgading)

\section{Analisis Zona Kerentanan Pergerakan Tanah di Lokasi Penelitian}

Hasil identifikasi zona kerentanan pergerakan tanah metode tak langsung yang mengacu pada SNI Penyusunan Peta Zona Kerentanan Gerakan Tanah (SNI 13-7124-2005) menunjukkan bahwa sebagian wilayah Poncokusumo dan Wajak terbagi menjadi tiga klasifikasi zona kerentanan gerakan tanah yaitu: sangat rendah, rendah dan menengah. Persentase daerah dengan tingkat kerentanan gerakan 
tanah rendah adalah sebesar 80,4\% (3700 Ha), untuk daerah dengan tingkat kerentanan gerakan tanah sangat rendah sebesar 10,9\% (500 Ha), dan untuk daerah dengan tingkat kerentanan gerakan tanah menengah sebesar 8,7\% (400 Ha). Daerah yang termasuk kedalam klasifikasi sangat rendah berada di Desa Karanganyar, sebagian Desa Dawuhan dan Patokpicis. Klasifikasi rendah berada di Desa Wajak, Blayu, Sumberejo, Pandansari, Ngadirejo dan sebagian Desa Patokpicis. Klasifikasi menengah berada di sebagian Desa Patokpicis.

Berdasarkan peta zona kerentanan gerakan tanah dapat diketahui bahwa klasifikasi zona kerentanan gerakan tanah sangat dipengaruhi oleh kondisi geologi dan morfologi wilayah. Hal tersebut dapat terlihat dari persebaran zona kerentanan gerakan tanahnya. Sebagian besar daerah dengan tingkat kerentanan gerakan tanah menengah berada pada formasi Qvom2 yang tersusun atas material Gunungapi Tua G. Mahameru. Pada umumnya material hasil gunungapi tua sudah bersifat lapuk serta lapisan tanahnya yang tebal dan gembur. Selain itu, daerah tersebut juga memiliki morfologi yang bergelombang dengan lereng yang miring hingga curam. Sehingga, rawan untuk terjadi gerakan tanah terutama ketika terjadi hujan dengan intensitas yang tinggi. Sementara itu, daerah dengan tingkat kerentanan gerakan tanah rendah dan sangat rendah berada pada formasi Qvf, Qvt dan Qvtl yang umumnya tersusun atas lahar dan endapan lahar. Pada dasarnya material tersebut merupakan material yang bersifat lepas dan tidak stabil. Namun, daerah tersebut berada pada morfologi yang datar hingga bergelombang dengan lereng yang landai hingga miring. Peta zona kerentanan gerakan tanah di sebagian wilayah Poncokusumo dan Wajak dapat dilihat dalam Gambar 6 sebagai berikut.

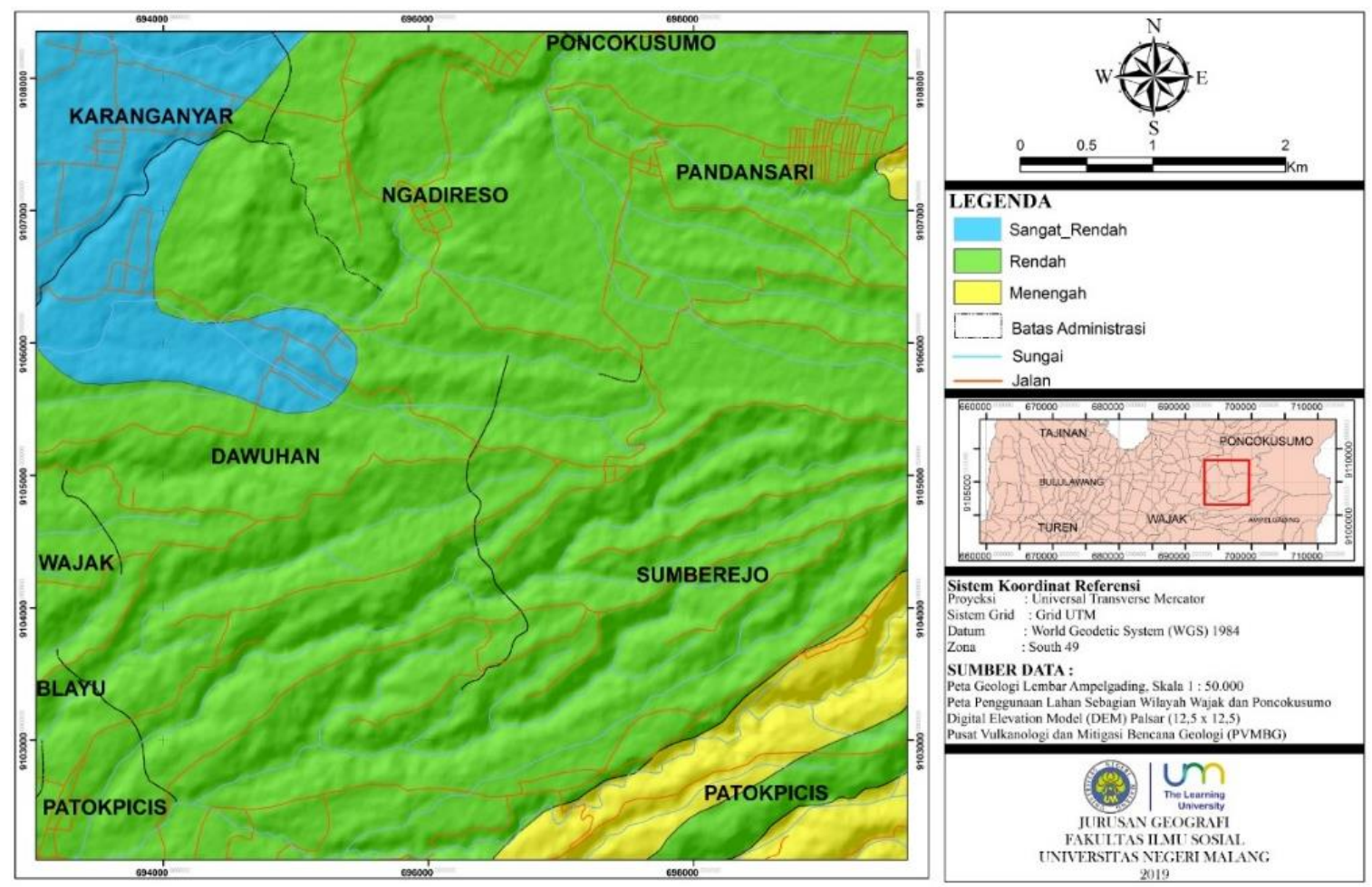

Gambar 6. Peta zona kerentanan gerakan tanah di sebagian wilayah Poncokusumo dan Wajak (Sumber: Analisis Peneliti, 2020)

\section{Pemetaan Bahaya Longsor Lahan di Lokasi Penelitian}

Tingkat bahaya longsor dipengaruhi dan ditentukan oleh karakteristik variable wilayahnya (Irawan et al., 2020). Hasil penentuan tingkat bahaya longsor lahan menunjukkan bahwa di sebagian wilayah Poncokusumo dan Wajak terbagi menjadi tiga klasifikasi tingkat bahaya longsor lahan yaitu: tidak berbahaya, rendah dan sedang. Persentase daerah dengan tingkat bahaya longsor lahan rendah adalah sebesar 18,7\% (860 Ha), untuk daerah dengan tingkat bahaya longsor lahan sedang sebesar 8\% (365 $\mathrm{Ha}$ ), dan untuk daerah tidak berpotensi sebesar 73,3\% (3375 Ha). Berdasarkan hasil tersebut dapat diketahui bahwa terdapat 26,7\% atau $1225 \mathrm{Ha}$ daerah yang rawan longsor. 
Tingkat bahaya longsor lahan didapatkan dari hasil skoring dan overlay antara peta kemiringan lereng $>15 \%$ dan peta kerawanan gerakan tanah. Tingkat bahaya longsor lahan juga dipengaruhi oleh beberapa faktor antara lain: penggunaan lahan, geologi, bentuk lahan, kemiringan lereng serta wilayah rawan gerakan tanah. Berdasarkan peta zona bahaya longsor lahan dapat diketahui bahwa klasifikasi bahaya longsor lahan sangat dipengaruhi oleh kondisi geologi dan morfologi wilayah. Hal tersebut dapat terlihat dari persebaran zona bahaya longsor lahannya. Sebagian besar daerah dengan tingkat bahaya longsor lahan sedang berada pada formasi Qvom2 yang tersusun atas material Gunungapi Tua Mahameru, Qvt yang tersusun atas material endapan Gunungapi Tengger dan formasi Qvt yang tersusun atas material lahar Gunungapi Mahameru. Pada umumnya material hasil gunungapi bersifat lepas serta lapisan tanahnya yang tebal dan gembur. Selain itu, daerah tersebut juga memiliki morfologi yang bergelombang, lembah-lembah dengan lereng yang miring hingga curam hasil aliran lahar dan air yang berbentuk $\mathrm{V}$ khas daerah vulkan. Sehingga, rawan untuk terjadi gerakan tanah terutama ketika terjadi hujan dengan intensitas yang tinggi.

Tingkat bahaya longsor lahan rendah memiliki luas $860 \mathrm{Ha}$ tersebar di bagian tenggara wilayah penelitian. Tingkat bahaya longsor lahan mencakupi wilayah dengan penggunaan lahan tegalan, dan hutan. Hal ini menunjukkan bahwa daerah tersebut memiliki potensi terjadinya bencana tanah longsor relatif kecil atau jarang. Menurut Hasibuan \& Rahayu (2017) penggunaan lahan dengan klasifikasi bahaya tanah longsor rendah didominasi oleh hutan. Penggunaan lahan memiliki faktor pemicu yang bersifat eksternal. Penggunaan lahan memiliki intensitas dalam aktivitasnya yang berbeda. Aktivitas yang semakin tinggi pada suatu penggunaan lahan maka akan menurunkan stabilitas lereng pada suatu wilayah.

Wilayah dengan stabilitas yang rendah akan meningkatkan bahaya longsor lahan. Kawasan hutan pada umumnya memiliki vegetasi yang rapat, sehingga vegetasi tersebut dapat menahan tanah agar tidak mudah longsor. Selain itu, wilayah hutan memiliki sedikit aktivitas yang dilakukan pada daerah lereng. Minimnya aktivitas yang dilakukan tersebut mengakibatkan stabilitas lereng di daerah hutan terjaga. Stabilitas lereng yang terjaga mengakibatkan tingkat bahaya longsor suatu wilayah menjadi minim. Faktor lain seperti kemiringan lereng memberikan kontribusi dalam meningkatkan atau menurunkan bahaya longsor. Wilayah yang memiliki tingkat kemiringan lereng tinggi maka bahaya longsor akan meningkat. Pada wilayah kajian, kemiringan lereng untuk daerah dengan tingkat bahaya longsor rendah memiliki kemiringan lereng dalam kategori sedang. Faktor kemiringan lereng akan membuat batuan maupun tanah mudah bergerak dengan bantuan faktor lainnya. Faktor antara kemiringan lereng dan penggunaan lahan memiliki kontribusi bersama dalam meningkatkan tingkat bahaya tanah longsor di suatu wilayah.

Tingkat bahaya longsor lahan sedang memiliki luas $365 \mathrm{Ha}$ tersebar di bagian tenggara wilayah penelitian. Tingkat bahaya tanah longsor mencakup wilayah dengan penggunaan lahan tegalan, dan permukiman. Hal ini menunjukkan bahwa daerah tersebut memiliki potensi terjadinya bencana tanah longsor relatif sedang. Kawasan permukiman memiliki sejumlah aktivitas yang dilakukan pada daerah lereng. Cukup banyaknya aktivitas yang dilakukan tersebut mengakibatkan stabilitas lereng di daerah tersebut berkurang. Stabilitas lereng yang menurun mengakibatkan tingkat bahaya longsor suatu wilayah menjadi meningkat. Faktor lain seperti kemiringan lereng memberikan kontribusi dalam meningkatkan atau menurunkan bahaya longsor. Wilayah yang memiliki tingkat kemiringan lereng tinggi maka bahaya longsor akan meningkat. Pada wilayah kajian, kemiringan lereng untuk daerah dengan tingkat bahaya longsor sedang memiliki kemiringan lereng dalam kategori tinggi. Faktor kemiringan lereng akan membuat batuan maupun tanah mudah bergerak dengan bantuan faktor lainnya. Faktor antara kemiringan lereng dan penggunaan lahan memiliki kontribusi bersama dalam meningkatkan tingkat bahaya tanah longsor di suatu wilayah.

Kemiringan lereng bukan satu-satunya faktor yang menyebabkan terjadinya longsor lahan tetapi juga karena tindakan masyarakat. Penggunaan lahan memiliki pengaruh dalam tingkat bahaya longsor. Menurut Tejo et al., (2016) penggunaan lahan memiliki nilai positif dalam mempengaruhi kejadian longsor. Daerah permukiman di sebagian wilayah Poncokusumo dan Wajak masuk pada zona bahaya rendah dan sedang. Hal tersebut senada dengan hasil penelitian Kumajas (2006) yang menunjukkan 
bahwa, penggunaan lahan permukiman yang tidak layak huni mengakibatkan percepatan longsor. Selain itu, adanya pembangunan jalan yang memotong lereng juga menambah tingkat potensi bahaya longsor.

Berdasarkan survei lapangan dapat diketahui bahwa di sebagian wilayah Poncokusumo dan Wajak terdapat 13 titik terjadinya longsor lahan. Lokasi terjadinya longsor lahan tersebut tersebar dan umumnya berada di daerah pemukiman, tegalan dan tepi sungai yang memiliki kemiringan lebih dari 15\%. Selain itu, titik longsor juga banyak dijumpai di tepi jalan yang memotong lereng. Peta persebaran titik longsor lahan di sebagian wilayah Poncokusumo dan Wajak dapat dilihat dalam Gambar 7.

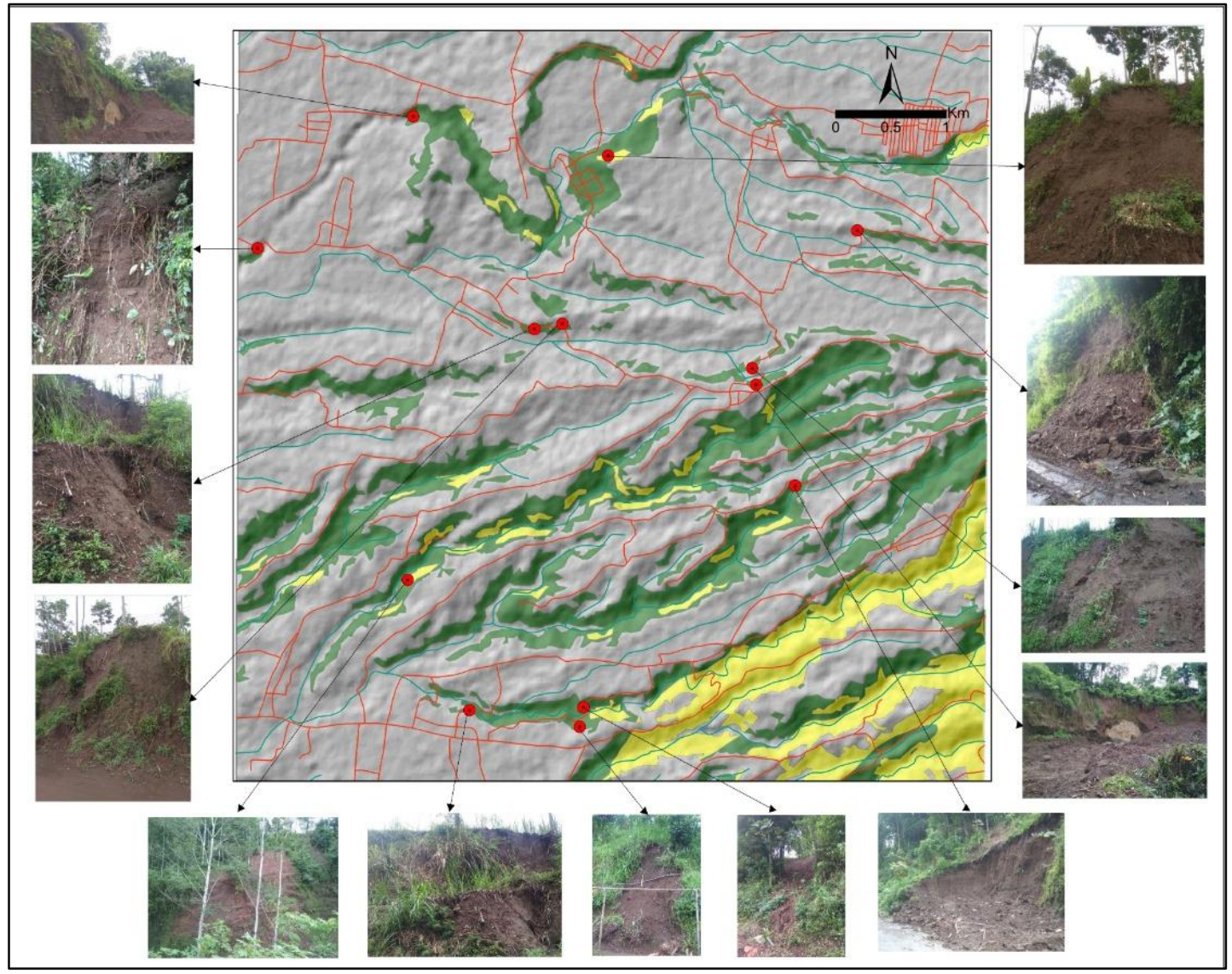

Gambar 7. Peta Lokasi Persebaran Longsor Lahan di sebagian wilayah Poncokusumo dan Wajak (Sumber: Analisis Peneliti, 2020)

\section{SIMPULAN}

Berdasarkan hasil tingkat bahaya bencana tanah longsor di lokasi penelitian diketahui bahwa terdapat tingkat bahaya sangat rendah, rendah, dan menengah. Daerah yang termasuk kedalam klasifikasi sangat rendah adalah Desa Karnganyar, sebagian Desa Dawuhan dan Patokpicis. Klasifikasi rendah berada di Desa Wajak, Blayu, Sumberejo, Pandansari, Ngadirejo dan sebagian Desa Patokpicis. Klasifikasi menengah berada di sebagian Desa Patokpicis. Persebaran tingkat bahaya rendah dan sedang berada di bagian tenggara wilayah kajian. Tingkat bahaya bencana tanah longsor rendah didominasi oleh penggunaan lahan hutan. Tingkat bahaya bencana longsor sedang didominasi oleh penggunaan lahan permukiman. Luas wilayah dengan tingkat bahaya rendah adalah $860,8 \mathrm{Ha}$ dan luas tingkat bahaya sedang adalah $365,1 \mathrm{Ha}$.

\section{DAFTAR PUSTAKA}

Bachri, S., Irawan, L. Y., Utaya, S., Nurdiansyah, F. D., Nurjanah, A. E., Tyas, L. W. N., ... \& Purnama, D. S. (2019, June). Landslide Susceptibility Mapping (LSM) in Kelud Volcano Using Spatial Multi-Criteria Evaluation. In IOP Conference Series: Earth and Environmental Science (Vol. 273, No. 1, p. 012014). IOP Publishing. 
BNPB. (2016). Risiko Bencana Indonesia. Jakarta: BNPB.

Buchori, I., \& Susilo, J. (2012). Model Keruangan untuk Identifikasi Kawasan Rawan Longsor. Tataloka, 14(4), 282-294.

Dibyosaputro, S. (1997). Geomorfologi Dasar. Yogyakarta: Fakultas Geografi UGM.

Feizizadeh, B., \& Blaschke, T. (2011). Landslide Risk Assessment Based on GIS Multi-Criteria Evaluation: A Case Study in Bostan-Abad County, Iran. Journal of Earth Science and Engineering, 1(1), 66-77.

Hasibuan, H. C., \& Rahayu, S. (2017). Kesesuaian Lahan Permukiman pada Kawasan Rawan Bencana Tanah Longsor di Kabupaten Temanggung. Teknik. PWK (Perencanaan Wilayah Kota), 6(4), 242256.

Irawan, L. Y., Syafi'i, I. R., Rosyadi, I., Siswanto, Y., Munawaroh, A., Wardhani, A. K., \& Saifanto, B. A. (2020). Analisis Kerawanan Longsor di Kecamatan Jabung, Kabupaten Malang. Jurnal Pendidikan Geografi, 25(2), 102-113.

Kumajas, M. (2006). Inventarisasi dan Pemetaan Rawan Longsor Kota Manado-Sulawesi Utara. Forum Geografi, 20(2), 190-197.

Moayedi, H., Osouli, A., Tien Bui, D., \& Foong, L. K. (2019). Spatial Landslide Susceptibility Assessment Based on Novel Neural-metaheuristic Geographic Information System Based Ensembles. Sensors, 19(21), 1-28.

Nursa'ban, M. (2010). Identifikasi Kerentanan dan Sebaran Longsor Lahan Sebagai Upaya Mitigasi Bencana di Kecamatan Bener Kabupaten Purworejo. Jurnal Geografi Gea, 10(2), 1-12.

Peraturan Kepala Badan Nasional Penanggulangan Bencana. 2012. Pedoman Umum Pengkajian Risiko Bencana. Jakarta: BNPB.

Permadi, M. G., Tjahjono, B., \& Baskoro, D. P. T. (2018). Identifikasi Daerah Risiko Bencana Longsor di Kota Bogor. Jurnal Tanah dan Lingkungan, 20(2), 86-94.

Pradana, I. H., Irawan, L. Y., Setiawan, D., Yuliano, F. S., \& Mufid, H. A. (2020). Analisis Daerah Tergenang Banjir di Desa Sitiarjo, Kabupaten Malang Menggunakan Data SAR (Synthetic Aperture Radar) Sentinel-1. Jurnal Georafflesia: Artikel Ilmiah Pendidikan Geografi, 5(1), 58-67.

Pradhan, A. M. S., \& Kim, Y. T. (2016). Evaluation of a combined spatial multi-criteria evaluation model and deterministic model for landslide susceptibility mapping. Catena, 140, 125-139.

Priyono, K. D. (2012). Integrasi Analisis Model Medan Digital dan Pedogeomorfik untuk Identifikasi Kejadian Bencana Longsorlahan.

Priyono, K. D., \& Priyana, Y. (2006). Analisis Tingkat Bahaya Longsor Tanah Di Kecamatan Banjarmangu Kabupaten Banjarnegara. Forum Geografi, 20(2), 175-189.

Ramadhani, N. I., \& Idajati, H. (2017). Identifikasi tingkat bahaya bencana longsor, studi kasus: kawasan lereng gunung lawu, kabupaten karanganyar, jawa tengah. Jurnal Teknik ITS, 6(1), 87-90.

Salim, M., \& Agustina, S. (2018). Partisipasi Kelompok Tani dalam Usaha Konservasi Tanah di Desa Sukaraja Kecamatan Praya Timur Kabupaten Lombok Tengah. Geodika: Jurnal Kajian Ilmu dan Pendidikan Geografi, 2(1), 46-53.

Santosa, L. W. (2006). Kajian Hidrogeomorfologi Mataair di Sebagian Lereng Barat Gunungapi Lawu. Forum Geografi, 20(1), 68-85.

SNI. 2005. Penyusunan Peta Zona Kerentanan Gerakan Tanah. Jakarta: Badan Standarisasi Nasional.

Tejo, R. K., Baskoro, D. P. T., \& Barus, B. (2016). Regresi Logistik Biner dan Rasional Untuk Analisis Bahaya Tanah Longsor di Kabupaten Cianjur. Jurnal Ilmu Tanah dan Lingkungan, 18(1), 35-41. 
Wahyuningrum, N., \& Supangat, A. B. (2016). Identifikasi Tingkat Bahaya Longsor dengan Skala Data Berbeda untuk Perencanaan DAS Mikro Naruwan, Sub DAS Keduang. Majalah Ilmiah Globe, 18(2), 53-60.

Wang, L. J., Guo, M., Sawada, K., Lin, J., \& Zhang, J. (2016). A comparative study of landslide susceptibility maps using logistic regression, frequency ratio, decision tree, weights of evidence and artificial neural network. Geosciences Journal, 20(1), 117-136.

Zhao, C., \& Lu, Z. (2018). Remote sensing of landslides-a review. Remote Sensing. MDPI AG. 